\title{
VARIABILIDADE GENÉTICA DE ACESSOS DE MARACUJÁ-SUSPIRO COM BASE EM MARCADORES MOLECULARES ${ }^{1}$
}

\author{
KEIZE PEREIRA JUNQUEIRA², FÁBIO GELAPE FALEIRO ${ }^{3}$, JOSÉ DARLAN RAMOS ${ }^{4}$, GRACIELE BELLON ${ }^{5}$, \\ NILTON TADEU VILELA JUNQUEIRA ${ }^{3}$, MARCELO FIDELES BRAGA ${ }^{3}$
}

RESUMO - Passiflora nitida é uma espécie silvestre amplamente distribuída pelo território brasileiro, constituindo-se em fonte de resistência a doenças foliares e de raízes. O objetivo deste trabalho foi avaliar a variabilidade genética entre acessos de $P$. nitida procedentes de diferentes tipos fitofisionômicos de Cerrado e estados brasileiros (Goiás, Distrito Federal, Tocantins, Mato Grosso e Amazonas), usando marcadores moleculares RAPD. O DNA genômico de cada acesso foi extraído, e doze iniciadores decâmeros foram utilizados para a obtenção de marcadores moleculares RAPD, que foram convertidos em matriz de dados binários, a partir da qual foram estimadas as distâncias genéticas entre os acessos e realizadas análises de agrupamento e de dispersão gráfica. Foram obtidos 196 marcadores para P. nitida, dos quais 63,81\% foram polimórficos. As distâncias genéticas entre os acessos de maracujá variaram de 0,031 a 0,614 e, considerando apenas $P$. nitida, de 0,031 a 0,417. Os marcadores moleculares demonstraram alta variabilidade genética dos acessos de P. nitida. Menores distâncias genéticas foram verificadas entre os acessos originados do mesmo estado. Considerando-se os acessos de um mesmo estado, menores distâncias genéticas foram verificadas entre os acessos provenientes de tipos fitofisionômicos próximos. O acesso "Manaus 2" apresentou o maior distanciamento genético em relação aos demais acessos. Termos para indexação: RAPD, Passiflora nitida Kunth,origem geográfica, tipos fitofisionômicos, variabilidade intraespecífica.

\section{GENETIC VARIABILITY OF WILD PASSION FRUIT DETERMINED BY MOLECULAR MARKERS}

\begin{abstract}
Passiflora nitida is a wild species widely distributed in Brazilian territory. It is a source of resistance to foliar and soil borne diseases. The objective of this work was to evaluate the genetic variability among accessions of $P$. nitida proceeding from different types of Cerrado (Brazilian savannah) vegetation and brazilian states (Goiás, Distrito Federal, Tocantins, Mato Grosso and Amazonas) using RAPD molecular markers. The genomic DNA of each origin was extracted and amplified using 12 decamer primers to obtain RAPD molecular markers. These markers were transformed in binary matrix data to estimate genetic distances among accessions and to perform cluster and graphical dispersion analysis. It was obtained 196 markers, of which $63.81 \%$ were polymorphic to $P$. nitida acessions. The genetic distances among accessions of Passiflora species ranged from 0.031 to 0.614 and among $P$. nitida accessions ranged from 0.031 to 0.417 . It was observed high genetic variability among $P$. nitida accessions. Lower genetic distances was verified among accessions of the same brazilian state. In the same state, lower genetic distances was found among accessions from similar Cerrado vegetations types. The accession named "Manaus 2" presented greatest genetic distance in comparison with others accessions.
\end{abstract}

Index terms: RAPD, Passiflora nitida Kunth,geographic localizations, Cerrado vegetations types, intraspecific variability.

\section{INTRODUÇÃO}

Passiflora nitida Kunth. é uma espécie de maracujá amplamente distribuída no território nacional. Acessos silvestres dessa espécie já foram coletados nos Estados do Amazonas, Pará, Piauí, Mato Grosso, Tocantins, Goiás, Bahia, Minas Gerais e Distrito Federal. No Cerrado, essa espécie pode ser facilmente encontrada em Matas Ciliares, Veredas, Cerradão, Cerrado stricto sensu e até em Matas Secas.

A espécie é relatada como rústica, tolerante à bacteriose, antracnose e a doenças causadas por patógenos do solo
(Menezes et al., 1994; Oliveira et al., 1994). Dessa forma, apresenta grande potencial para ser utilizada no melhoramento genético e como porta-enxerto para a espécie comercial de $P$. edulis $\mathrm{f}$. flavicarpa, conforme relatado por Chaves et al. (2004). Outro potencial da espécie é a sua utilização per si, como relatado por Oliveira \& Ruggiero (2005).

Por ter muita similaridade botânica com o maracujazeirodoce ( $P$. alata Curtis), acredita-se que seu potencial seja ainda maior como fonte de resistência a várias doenças dessa espécie, cujo cultivo, no Brasil, vem sendo limitado pela incidência severa da bacteriose (Xanthomonas axonopodis pv. passiflorae), da

\footnotetext{
'(Trabalho: 057-06). Recebido: 04-05-2006. Aceito para publicação em: 02-07-2007. Apoio financeiro: CAPES e Embrapa Cerrados. Parte da Dissertação de Mestrado do primeiro autor.

${ }^{2}$ Eng. Agr. Mestranda em Fitotecnia/Universidade Federal de Lavras, Caixa Postal 3037, 37200-000 Lavras-MG. E-mail: keize@ufla.br.

${ }^{3}$ Pesquisador da Embrapa Cerrados, BR 020, Km 18, Caixa Postal 08223, 73010-970 Planaltina-DF.E-mail: ffaleiro@cpac.embrapa.br, junqueir@cpac.embrapa.br, fideles@cpac.embrapa.br.

${ }^{4}$ Professor da Universidade Federal de Lavras, Caixa Postal 3037, 37200-000 Lavras-MG.E-mail: darlan@ufla.br.

Eng. Agr. Mestranda em Ciências Agrárias/Universidade de Brasília, Câmpus Universitário Darcy Ribeiro, $70910-900$ Brasília-DF.E-mail: bellon@cpac.embrapa.br.
} 
podridão-do-pé (Fusarium solani), da antracnose (Colletotrichum gloeosporioides Penz.) e da virose do endurecimento do fruto (Cowpea aphid-borne mosaic virusCABMV e Passion fruit woodiness virus - PWV).

Entre os acessos de P. nitida mantidos na coleção da Embrapa Cerrados, oriundos de várias regiões do País, pode-se observar uma grande variabilidade fenotípica entre formatos e tamanho de frutos, espessura de casca, aroma, cor da casca e da polpa, sabor, bem como na produtividade e resistência a doenças foliares. Para complementar tais observações, objetivou-se realizar o estudo da variabilidade genética de 17 acessos de $P$. nitida mantidos no banco de germoplasma da Embrapa Cerrados por meio de marcadores moleculares RAPD ("Random Amplified Polymorphic DNA").

\section{MATERIAL E MÉTODOS}

O trabalho foi realizado no Laboratório de Genética e Biologia Molecular da Embrapa Cerrados. Foram analisados 17 acessos de Passiflora nitida. Um acesso de P. edulis f. flavicarpa e um de P. alata foram utilizados como "outgroups" (Tabela 1). Folhas em estágio intermediário de maturação foram coletadas, e o DNA genômico extraído, utilizando o método do CTAB com algumas modificações (Faleiro et al., 2003).

Amostras de DNA de cada material genético foram amplificadas para obtenção de marcadores RAPD. As reações de amplificação foram feitas em um volume total de $13 \mu \mathrm{L}$, contendo Tris- $\mathrm{HCl} 10 \mathrm{mM}$ (pH 8,3); $\mathrm{KCl} 50 \mathrm{mM} ; \mathrm{MgCl}_{2} 3 \mathrm{mM}$; $100 \mu \mathrm{M}$ de cada um dos desoxiribonucleotídios (dATP, dTTP, dGTP e dCTP); 0,4 uM de um iniciador (Operon Technologies Inc., Alameda, CA, EUA), uma unidade da enzima Taq polimerase e, aproximadamente, $15 \mathrm{ng}$ de DNA. Foram utilizados 12 iniciadores decâmeros: OPD (04; 07; 08 e 16); OPE (18 e 20); OPF (01 e 14); OPG (08), e OPH (12; 16 e 17).

As amplificações foram efetuadas em termociclador programado para 40 ciclos, cada um constituído pela seguinte seqüência: 15 segundos a $94{ }^{\circ} \mathrm{C} ; 30$ segundos a $35^{\circ} \mathrm{C}$, e 90 segundos a $72{ }^{\circ} \mathrm{C}$. Após os 40 ciclos, foi feita uma etapa de extensão final de seis minutos a $72^{\circ} \mathrm{C}$ e, finalmente, a temperatura foi reduzida para $4{ }^{\circ} \mathrm{C}$. Após a amplificação, foram adicionados, a cada amostra, $3 \mu \mathrm{l}$ de uma mistura de azul de bromofenol $(0,25 \%)$ e glicerol $(60 \%)$ em água. Essas amostras foram aplicadas em gel de agarose $(1,2 \%)$, corado com brometo de etídio, submerso em tampão TBE (Tris-Borato $90 \mathrm{mM}$, EDTA $1 \mathrm{mM}$ ). A separação eletroforética foi de, aproximadamente, quatro horas, a 90 Volts. Ao término da corrida, os géis foram fotografados sob luz ultravioleta.

Os marcadores RAPD gerados foram convertidos em matriz de dados binários, a partir da qual foram estimadas as distâncias genéticas entre os diferentes acessos, com base no complemento do coeficiente de similaridade de Nei \& Li (1979), utilizando-se do Programa Genes (Cruz, 1997). A matriz de distâncias genéticas foi utilizada para realizar análises de agrupamento por meio de dendrograma, utilizando-se do método do UPGMA (Unweighted pair-group arithmetic average) como critério de agrupamento, e a dispersão gráfica baseada em escalas multidimensionais, usando o método das coordenadas principais, com auxílio do Programa SAS e Statistica (Statsoft Inc., 1999).

\section{RESULTADOS E DISCUSSÃO}

Os 12 iniciadores decâmeros geraram um total de 196 marcadores RAPD, perfazendo uma média de 16,3 marcadores por iniciador. A Figura 1 ilustra o produto da amplificação de amostras de DNA, gerado pelo iniciador OPD-04 e evidencia vários marcadores polimórficos presentes no acesso Passiflora nitida "Manaus 2" e nos "outgroups" . Do total de marcadores, considerando-se apenas os acessos de P. nitida, 125 (72,25\%) foram polimórficos (Tabela 2). A alta média de marcadores por iniciador e a alta porcentagem de marcadores polimórficos dentro da espécie $P$. nitida evidenciam a presença de alta variabilidade genética intra-específica. Uma alta variabilidade genética interespecífica foi verificada ao analisar as bandas polimórificas dos acessos de P. edulis f. flavicarpa e P. alata ("outgroups") em relação aos acessos de P. nitida. Faleiro et al. (2004), Pio Viana et al. (2003) e Crochemore et al. (2003) já haviam relatado a alta variabilidade genética interespecífica no gênero Passiflora.

As distâncias genéticas entre os 19 acessos de maracujá variaram entre 0,031 e 0,614 (Tabela 3 ), sendo que os maiores valores observados se referem a distância entre as espécies comerciais ( $P$. edulis f. flavicarpa e $P$. alata) e os acessos de $P$. nitida. Considerando apenas os acessos de $P$. nitida, as distâncias genéticas variaram entre 0,031 a 0,417 , com uma média de 0,209 . O acesso que mais diferenciou dos demais foi o "Manaus-2" com uma distância média de 0,388.

A partir da análise de agrupamento realizada com base nas distâncias genéticas, subdividiram os 19 acessos em, pelo menos, sete grupos de similaridade genética, sendo cinco grupos dentro da espécie Passiflora nitida (Figura 2). Observou-se que os agrupamentos dos acessos de $P$. nitida se relacionaram com a origem geográfica dos mesmos. As distâncias entre os acessos e a distribuição dos mesmos nos grupos de similaridade podem ser também observadas no gráfico de dispersão (Figura 3).

O maior grupo foi formado por 8 acessos, todos procedentes do Distrito Federal e Goiás. Dentro deste grupo, pode-se verificar maior similaridade entre os acessos $P$. nitida "São José" de Vereda e $P$. nitida "Jardim Botânico" de Cerradão $(0,031)$, e entre $P$. nitida "Vale do Amanhecer" de Vereda e $P$. nitida "Silvânia" de Mata Ciliar $(0,033)$. Dentro deste grupo, o material que mais se distanciou geneticamente foi $P$. nitida "Corumbá" de Mata Seca, que corresponde a um material originário de uma fitofisionomia mais seca. Por outro lado, os acessos procedentes de alguns tipos fitofisionômicos mais úmidos, como Mata Ciliar e Vereda, aproximaram-se mais sob o ponto de vista genético.

Também foram formados grupos envolvendo acessos de P. nitida procedentes de Tocantins, Mato Grosso e Amazonas, com exceção de "Manaus 2", que se distanciou muito dos acessos procedentes do Amazonas e dos demais. Tal acesso revelou distância genética de até 0,416 em relação a outro acesso da mesma espécie, P. nitida "Itiquira 1". Considerando-se toda a base genética do gênero Passiflora já estudada (Faleiro et al., 
TABELA 1 - Espécies de maracujazeiro e respectivos acessos.

\begin{tabular}{|c|c|c|c|c|}
\hline $\mathbf{N}^{\mathbf{0}}$ & Espécie & Acesso & Estado & Código \\
\hline 1 & Passiflora nitida Kunth. & "N. R. São José" (Chapada) & DF & CPAC MJ-01-01 \\
\hline 2 & Passiflora nitida Kunth. & "N. R. São José" (Vereda) & DF & CPAC MJ-01-02 \\
\hline 3 & Passiflora nitida Kunth. & "Vale do Amanhecer" (Vereda) & DF & CPAC MJ-01-03 \\
\hline 4 & Passiflora nitida Kunth. & "Jardim Botânico" (Cerradão) & DF & CPAC MJ-01-04 \\
\hline 5 & Passiflora nitida Kunth. & "Silvânia" (Mata Ciliar) & GO & CPAC MJ-01-05 \\
\hline 6 & Passiflora nitida Kunth. & "Silvânia" (Chapada) & GO & CPAC MJ-01-06 \\
\hline 7 & Passiflora nitida Kunth. & "Alto Paraíso" (Mata Ciliar) & GO & CPAC MJ-01-09 \\
\hline 8 & Passiflora nitida Kunth. & "Corumbá" (Mata seca) & GO & CPAC MJ-01-10 \\
\hline 9 & Passiflora nitida Kunth. & "Itiquira 1" & MT & CPAC MJ-01-07 \\
\hline 10 & Passiflora nitida Kunth. & "Itiquira 2" & MT & CPAC MJ-01-08 \\
\hline 11 & Passiflora nitida Kunth. & "Natividade" & TO & CPAC MJ-01-11 \\
\hline 12 & Passiflora nitida Kunth. & "Natividade" (Com. Casa de Telha) & TO & CPAC MJ-01-12 \\
\hline 13 & Passiflora nitida Kunth. & "Natividade" (Com. do Brejão) & TO & CPAC MJ-01-13 \\
\hline 14 & Passiflora nitida Kunth. & "Palmas-TO" & TO & CPAC MJ-01-14 \\
\hline 15 & Passiflora nitida Kunth. & "Manaus 1" (Rio Urubu) & AM & CPAC MJ-01-15 \\
\hline 16 & Passiflora nitida Kunth. & "Manaus 2"(Distrito Agropecuário) & AM & CPAC MJ-01-16 \\
\hline 17 & Passiflora nitida Kunth. & "Manaus 3" & AM & CPAC MJ-01-17 \\
\hline 18 & Passiflora alata comercial & "Seleção FAL" & DF & CPAC MJ-02-11 \\
\hline 19 & Passiflora edulis f. flavicarpa & "GA-2" & DF & CPAC MJ-M-01 \\
\hline
\end{tabular}

TABELA 2 - Iniciadores utilizados para a obtenção dos marcadores RAPD e respectivos números de bandas polimórficas e monomórficas, considerando-se apenas os acessos de $P$. nitida.

\begin{tabular}{lccc}
\hline Iniciador & Seqüência $\mathbf{5}^{\prime} \rightarrow \mathbf{3}^{\prime}$ & $\begin{array}{c}\mathbf{N}^{\mathbf{0}} \text { de bandas } \\
\text { polimórficas }\end{array}$ & $\begin{array}{c}\mathbf{N}^{\mathbf{0}} \text { de bandas } \\
\text { monomórficas }\end{array}$ \\
\hline OPD-04 & TCTGGTGAGG & 16 & 13 \\
OPD-07 & TTGGCACGGG & 27 & 1 \\
OPD-08 & GTGTGCCCCA & 8 & 5 \\
OPD-16 & AGGGCGTAAG & 12 & 9 \\
OPE-18 & GGACTGCAGA & 2 & 6 \\
OPE-20 & AACGGTGACC & 7 & 4 \\
OPF-01 & ACGGATCCTG & 3 & 7 \\
OPF-14 & TGCTGCAGGT & 12 & 5 \\
OPG-08 & TCACGTCCAC & 9 & 3 \\
OPH-12 & ACGCGCATGT & 15 & 4 \\
OPH-16 & TCTCAGCTGG & 6 & 7 \\
OPH-17 & CACTCTCCTC & 8 & 7 \\
\hline \multicolumn{7}{c}{ TOTAL } & $\mathbf{1 2 5}$ & $\mathbf{7 1}$ \\
\hline
\end{tabular}

TABELA 3 - Matriz de distâncias entre 19 acessos de maracujazeiro, baseada em 196 marcadores RAPD.

\begin{tabular}{|c|c|c|c|c|c|c|c|c|c|c|c|c|c|c|c|c|c|c|}
\hline & 1 & 2 & 3 & 4 & 5 & 6 & 7 & 8 & 9 & 10 & 11 & 12 & 13 & 14 & 15 & 16 & 17 & 18 \\
\hline 1 & - & & & & & & & & & & & & & & & & & \\
\hline 2 & 0,047 & - & & & & & & & & & & & & & & & & \\
\hline 3 & 0,080 & 0,040 & - & & & & & & & & & & & & & & & \\
\hline 4 & 0,063 & 0,031 & 0,037 & - & & & & & & & & & & & & & & \\
\hline 5 & 0,063 & 0,052 & 0,033 & 0,037 & $\begin{array}{lll}- & \\
\end{array}$ & & & & & & & & & & & & & \\
\hline 6 & 0,080 & 0,058 & 0,073 & 0,062 & 0,040 & - & & & & & & & & & & & & \\
\hline 7 & 0,099 & 0,064 & 0,091 & 0,082 & 0,092 & 0,073 & - & & & & & & & & & & & \\
\hline 8 & 0,125 & 0,092 & 0,116 & 0,115 & 0,112 & 0,100 & 0,095 & - & & & & & & & & & & \\
\hline 9 & 0,205 & 0,219 & 0,218 & 0,241 & 0,223 & 0,241 & 0,237 & 0,184 & - & & & & & & & & & \\
\hline 10 & 0,224 & 0,227 & 0,216 & 0,226 & 0,231 & 0,247 & 0,234 & 0,214 & 0,118 & - & & & & & & & & \\
\hline 11 & 0,193 & 0,195 & 0,170 & 0,176 & 0,153 & 0,176 & 0,169 & 0,188 & 0,236 & 0,185 & - & & & & & & & \\
\hline 12 & 0,265 & 0,260 & 0,263 & 0,256 & 0,228 & 0,236 & 0,231 & 0,238 & 0,303 & 0,283 & 0,110 & - & & & & & & \\
\hline 13 & 0,272 & 0,267 & 0,265 & 0,268 & 0,244 & 0,252 & 0,215 & 0,229 & 0,313 & 0,272 & 0,139 & 0,050 & - & & & & & \\
\hline 14 & 0,214 & 0,216 & 0,225 & 0,230 & 0,193 & 0,189 & 0,186 & 0,182 & 0,283 & 0,239 & 0,146 & 0,141 & 0,143 & - & & & & \\
\hline 15 & 0,238 & 0,217 & 0,225 & 0,244 & 0,212 & 0,209 & 0,210 & 0,198 & 0,298 & 0,263 & 0,227 & 0,229 & 0,215 & 0,179 & - & & & \\
\hline 16 & 0,391 & 0,395 & 0,403 & 0,396 & 0,368 & 0,351 & 0,399 & 0,372 & 0,416 & 0,371 & 0,394 & 0,404 & 0,405 & 0,320 & 0,417 & - & & \\
\hline 17 & 0,250 & 0,229 & 0,225 & 0,236 & 0,224 & 0,244 & 0,243 & 0,193 & 0,263 & 0,235 & 0,225 & 0,285 & 0,253 & 0,224 & 0,146 & 0,405 & - & \\
\hline 18 & 0,471 & 0,490 & 0,494 & 0,497 & 0,497 & 0,509 & 0,526 & 0,488 & 0,430 & 0,432 & 0,493 & 0,577 & 0,545 & 0,526 & 0,510 & 0,515 & 0,470 & - \\
\hline 19 & 0,581 & 0,550 & 0,556 & 0,528 & 0,573 & 0,559 & 0,564 & 0,552 & 0,569 & 0,527 & 0,540 & 0,552 & 0,583 & 0,559 & 0,563 & 0,614 & 0,524 & 0,475 \\
\hline
\end{tabular}




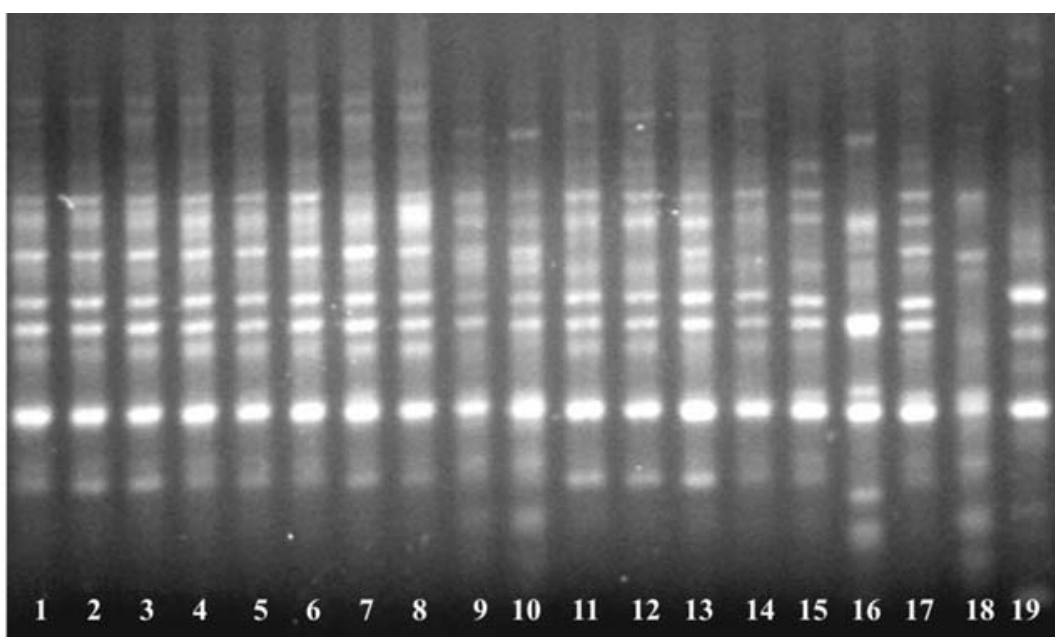

FIGURA 1 - Produto de amplificação de amostras de DNA genômico de 19 acessos de maracujazeiro obtidos com o uso do iniciador decâmero OPD-04. Os números correspondem aos acessos da Tabela 1.

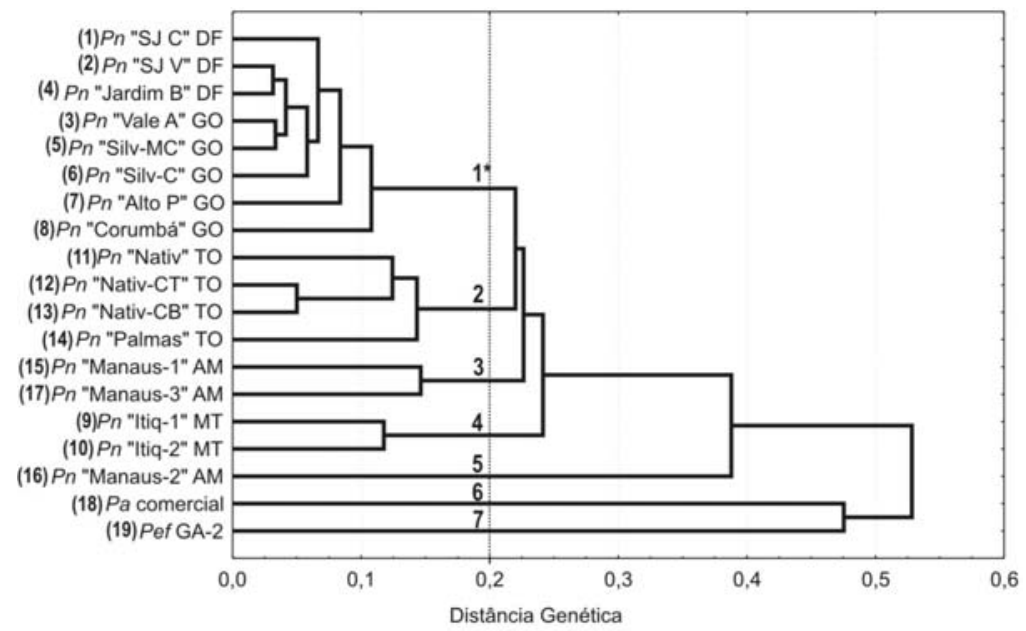

FIGURA 2 - Análise de agrupamento de 19 acessos de maracujazeiro com base na matriz de distâncias genéticas calculadas, utilizandose de 196 marcadores RAPD. O método do UPGMA foi utilizado como critério de agrupamento. Os números correspondem aos acessos da Tabela $1 .{ }^{*}$ grupos de similaridade genética.

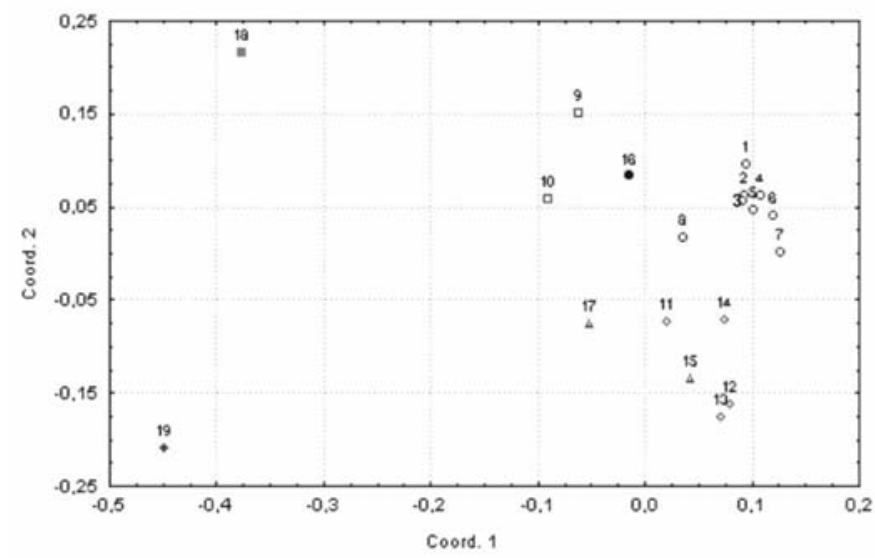

FIGURA 3 - Dispersão gráfica de 19 acessos de maracujazeiro com base na matriz de distâncias genéticas calculadas, utilizando-se de 196 marcadores RAPD. Os números correspondem aos acessos da Tabela 1. Acessos com o mesmo símbolo pertencem ao mesmo grupo de similaridade definido na Figura 2. 
2005; Bellon et al., 2005; Paula et al., 2005), este valor é bastante elevado. Portanto, há possibilidade de tal material ser um híbrido interespecífico de $P$. nitida com outra espécie geneticamente compatível ou constituir-se em outra espécie de Passiflora. Assim, trabalhos mais apurados envolvendo este acesso devem ser realizados tanto envolvendo os aspectos morfoagrônomicos quanto os genéticos.

\section{CONCLUSÃO}

Existe elevada variabilidade genética entre acessos de Passiflora nitida procedentes de diferentes estados. Dentro do mesmo estado, a variabilidade é menor, ocorrendo principalmente entre acessos procedentes de diferentes tipos fitofisionômicos. Tal variabilidade subsidia e mostra a importância de estudar os diversos acessos dessa espécie para fins de melhoramento, enxertia e utilização per si. A grande variabilidade genética intraespecífica de $P$. nitida também permite concluir que não se devem fazer generalizações sobre a espécie, considerando as expressivas diferenças genéticas entre acessos, principalmente de diferentes procedências. $\mathrm{O}$ acesso Manaus 2 deve ser mais estudado, tendo em vista o grande distanciamento genético em relação aos demais acessos de $P$. nitida.

\section{REFERÊNCIAS}

BELLON, G.; FALEIRO, F.G.; JUNQUEIRA, K.P.; PAULA, M.S.; BRAGA, M.F.; JUNQUEIRA, N.T.V.; PEIXOTO, J.R. Diversidade genética de acessos comerciais e silvestres de maracujazeirodoce com base nos marcadores RAPD. In: REUNIÃO TÉCNICA DE PESQUISAS EM MARACUJAZEIRO, 4., 2005. Planaltina, DF: Embrapa Cerrados, 2005. p.18-121.

CHAVES, R.C.; JUNQUEIRA, N.T.V.; MANICA, I. PEIXOTO, J.R.; PEREIRA, A.V.; FIALHO, J.F. Enxertia de maracujazeiro-azedo em estacas herbáceas enraizadas de espécies de passifloras nativas. Revista Brasileira de Fruticultura, Jaboticabal, v. 26, n. 1, p. 120-123, 2004

CROCHEMORE, M. L.; MOLINARI, H. B. C.; VIEIRA, L. G. E. Genetic diversity in passion fruit (Passiflora spp.) evaluated by RAPD markers. Brazilian Archives of biology and Technology, Curitiba, v. 46, n. 4, p. 521-527, 2003.

CRUZ, C.D. Programa genes: aplicativo computacional em genética e estatística. Viçosa: UFV, 1997. 442p.

FALEIRO, F.G.; FALEIRO, A.S.G.; CORDEIRO, M.C.R., KARIA, C.T. Metodologia para operacionalizar a extração de DNA de espécies nativas do cerrado. Planaltina: Embrapa Cerrados, 2003. 6p. (Comunicado Técnico, 92)
FALEIRO, F.G.; JUNQUEIRA, N.T.V.; BELLON, G.; BORGES, T.A.; ANJOS, J.R.N.; PEIXOTO, J.R.; BRAGA, M.F.; SANTOS, D.G. Diversidade genética de espécies silvestres de maracujazeiro com resistência múltipla a doenças com base em marcadores RAPD. Fitopatologia Brasileira, Brasília, v.29, p. S325, 2004. Suplemento

FALEIRO, F.G.; JUNQUEIRA, N.T.V.; BRAGA, M.F.; BELLON, G.; PEIXOTO, J.R. Diversidade genética de variedades comerciais de maracujazeiro-azedo com base em marcadores RAPD. In: In: REUNIÃO TÉCNICA DE PESQUISAS EM MARACUJAZEIRO, 4., 2005. Planaltina, DF: Embrapa Cerrados, 2005. p.05-109.

MENEZES, J.M.T., OLIVEIRA, J.C., RUGGIERO, C.,BANZATO, D. A. Avaliação da taxa de pegamento de enxertos de maracujáamarelo sobre espécies tolerantes à "morte prematura de plantas". Científica, São Paulo, v.22, n.1, p.95-104, 1994.

NEI, M.; LI, W.H. Mathematical model for studying genetic variation in terms of restriction endonucleases. Proceedings of the National Academy of Science USA, Melville, v.76, p. 52695273,1979 .

OLIVEIRA, J.C. de; NAKAMURA, K.; MAURO, A.O; CENTURION, M.A.P.C. Aspectos gerais do melhoramento do maracujazeiro. In: SÃO JOSÉ, A.R. Maracujá, produção e mercado. Vitória da Conquista: DFZ/UESB, 1994. p. 27-37.

OLIVEIRA, J.C. de; RUGGIERO, C. Espécies de maracujá com potencial agronômico. In: FALEIRO, F.G.; JUNQUEIRA, N.T.V.; BRAGA, M.F. Maracujá: germoplasma e melhoramento genético. Planaltina, DF: Embrapa Cerrados, 2005. p.143-158.

PAULA, M.S.; FALEIRO, F.G.; JUNQUEIRA, K.P.; BELLON, G.; JUNQUEIRA, N.T.V.; BRAGA, M.F.; PEIXOTO, J.R. Diversidade genética de espécies de Passiflora, potenciais fontes de resistência a doenças, com base em marcadores RAPD. In: REUNIÃO TÉCNICA DE PESQUISAS EM MARACUJAZEIRO, 4., 2005, Planaltina: DF: Embrapa Cerrados, 2005. p.100-104.

PIO VIANA, A.; PEREIRA, T. N. S.; PEREIRA, M. G.; SOUZA, M. M.; MALDONADO, F.; AMARAL JÚNIOR, A. T. Diversidade entre genótipos de maracujazeiro-amarelo (Passiflora edulis $\mathrm{f}$. flavicarpa) e entre espécies de passifloras determinada por marcadores RAPD. Revista Brasileira de Fruticultura, Jaboticabal, v.25, n.3, p.489-493, 2003.

STATSOFT INC. Statistica for Windows [Computer program manual]. Tulsa, OK: StatSoft, 1999. 